\title{
Management of Thyroglossal Duct Cyst
}

\author{
Ali I. Swaid and Ahmed Y. Al-Ammar
}

Department of Otolaryngology Head and Neck Surgery, King Abdulaziz university hospital, Riyadh, Saudi Arabia

\begin{abstract}
Abstrct: Objective: Is to review our cases of Thyroglossal duct cyst (TGDC) attempting to make some conclusions that may facilitate the management of such a cases.

Study Design: Twenty patients with the diagnosis of TGDC were managed between July 1996 and April 2007 in the department of Otolaryngology, King Abdul-Aziz University Hospital, Riyadh, Saudi Arabia.

Results: All of our cases underwent radiological assessment before surgical intervention. Eighteen patients underwent Sistrunk procedure. In two patients the treatment was limited to removal of the cyst. In seventeen patients the clinicoradiological diagnosis was in agreement with histopathological diagnosis of TGDC.

Conclusions: The diagnosis of TGDC in most of the cases is clinical. Combination of clinical assessment and imaging studies can improve the sensitivity for the diagnosis. Sistrunk's operation presented good results in our series with low rates of complications $(5 \%)$ and recurrence $(5.5 \%)$.
\end{abstract}

Keywords: Thyroglossal duct cyst, neck mass, congenital anomaly.

\section{INTRODUCTION}

Thyroglossal duct cysts develop from remnants of the thyroid anlage that descend from the foramen cecum on the base of the tongue between the fourth and seventh weeks of development [1]. The thyroid primordium passes either anterior, posterior, or through the hyoid bone in its descent in the midline of the neck. This leaves a possibility that thyroid remnants may persist at any site along this route and form cysts or fistulas [2].

TGDC usually present in young children, although they may be found in patients of any age. The most common clinical presentation of TGDC is a gradually enlarging painless mass in the midline of the neck in children or young adults [3]. The cyst is usually 2 to $4 \mathrm{~cm}$ in diameter. Occasionally TGDC may present with fistula, which is commonly as a result of infection drained surgically or spontaneously.

On physical examination, the mass is typically located at the midline of the anterior neck and moves upward with tongue protrusion, a reflection of its connection with the foramen cecum.

In most circumstances a meticulous clinical history and physical examination are sufficient to make a correct preoperative diagnosis

Imaging, on the other hand, is important to confirm the diagnosis, to identify the presence of functioning thyroid tissue in the neck, and to detect any possibility of malignant change within the cyst.

TGDC should be treated surgically as described by Sistrunk [4]. He described his procedure by excision of the cyst in continuity with the central part of the body of the hyoid

*Address correspondence to this author at the Department of Otolaryngology Head and Neck Surgery, King Abdulaziz university hospital, P.O. Box: 61419, Riyadh, 11565, Saudi Arabia; Tel: 966(1)4775735; Fax: 966(1)4775748; E-mail: ahmedalammar@hotmail.com bone and a core of tongue muscle up to the foramen cecum. The recurrence rate with this procedure drops to $3 \%$ to $4 \%$ based on different studies [5,6]. On the other hand local cyst excision is associated with a higher recurrence rate [7].

\section{PATIENTS AND METHODS}

Twenty consecutive patients with the diagnosis of thyroglossal duct cyst were managed between July 1996 and April 2007 in the department of Otolaryngology, King Abdul-Aziz University Hospital, Riyadh, Saudi Arabia.

Their charts were reviewed for the following data: age at presentation, sex, clinical characteristics of presentation, location of the cyst, duration of complaint, imaging study, clinical diagnosis, type of surgical procedures, surgical complications, number of surgeries per patient, histopathologic diagnosis, duration of follow up, and complications.

\section{RESULTS}

There were 14 male and 6 female (ratio of 2.3 to 1 ). The age ranged between 20 months and 53 years (mean age was 13.18 years) ( the median age was 9 years). Sixteen of them were under 16 years of age and only four patients were above 16 years of age.

Fifteen patients presented with only a midline neck mass, two patients presented with a recurrent draining fistula, and three patients presented with both symptoms.

The location of the mass or the opening in nineteen patients were at the sub-hyoid area, and only one patient was presented with sub mental opening.

Duration of the chief complaint was variable between 3 months and 18 years. In one patient there was history of acute stage which was treated by aspiration and oral antibiotic, culture of the aspirate showed Haemophilus influenzae.

All of the patients have radiologic assessment. Cervical ultrasonography was performed in twelve patients. Two patients underwent CT-scan and five patients underwent both 
U/S and CT-scan. Thyroid scan was done for only one patient.

Eighteen patients underwent sistrunk procedure; one of them had a history of prior cyst excision, and another one had a history of sistrunk procedure with recurrence.

In two patients the treatment was limited to removal of the cyst; one of them was followed up for 5 years with no recurrence.

All patients received prophylactic antibiotic postoperatively. Only one patient had infected wound, presented 6 days after the procedure and treated successfully by oral amoxycillin clavulanic acid.

All specimens underwent histopathological examination. The diagnosis of TGDC was based on Presence of respiratory (pseudostratified ciliated columnar) and/or squamous epithelial lining associated with a thyroglossal tract or thyroid follicles in the surrounding stroma. In seventeen patients the study was consistent with thyroglossal duct cyst. In the other three, histopathology revealed non-specific acute and chronic inflammatory changes with abscess formation in one of them, benign cystic lesion in the other, and epidermal inclusion cyst in the last.

The follow up period was ranging between three weeks and six months, except for one patient, was followed up for 5 years. One patient had recurrence and operated on one year later.

\section{DISCUSSION}

Thyroglossal duct cyst is the most common midline cervical anomaly encountered in children [2,8,9 Most TGDC present during the first 5 years of life, although the lesion has repeatedly been described during adulthood [10-12].

The mean age at presentation in our cases was 13.18 years. On the other hand males were affected more frequently compared to females in our study, ratio of 3.1: 1, which is in agreement with other studies [2].

Most TGDC present in the midline near the level of the hyoid bone. Based on the study by Allard [2], $60 \%$ of TGDC were located adjacent to the hyoid bone, $24 \%$ were between the hyoid and base of the tongue, $13 \%$ were between the hyoid and pyramidal lobe of the thyroid gland, and the remaining 3\% were intralingual. In our cases ninteen patients were located adjcent to hyoid bone $(95 \%)$ and one patient between the hyoid bone and base of the tongue (5\%).

Because of their anatomic association with the oral cavity, thyroglossal duct cysts are prone to infection. Up to onethird of patients may present with a concurrent or previous history of infection in the cyst. The risk of infection is the primary indication for surgical intervention. The most common responsible pathogens include Haemophilus influenzae, Staphylococcus aureus, and Staphylococcus epidermidis $[5,13]$. In our study only one patient $(5 \%)$ had history of infection and the culture showed Haemophilus influenzae.

Radiologically, an uncomplicated thyroglossal duct cyst may either appear on ultrasound as an anechoic, well circumscribed cyst with increased through transmission or be pseudosolid in appearance [14].
Thyroid ultrasound and radionucleotide scanning can differentiate ectopic thyroid from a thyroglossal duct cyst. However, ultrasound is readily available, inexpensive, noninvasive and does not involve ionizing radiation or use sedation, which is particularly important in children.

Preoperative sonographic identification of a normal thyroid gland in patients with thyroglossal duct cyst confirms a source of thyroid hormone and excludes ectopic thyroid [15]. Routine thyroid scintigraphy is therefore not necessary if a normal thyroid gland can be identified on routine preoperative US.

CT and MRI may play a supplementary role, in more accurately delineating the anatomy of the lesion, particularly with large cysts.

According to our data, combination of clinical and radiological assessment can result in a sensitivity of $85 \%$ in diagnosing TGDC.

The experience with fine-needle aspiration as an assessment tool for TGDS is limited [13].

In 1893 Schlange [16] proposed removal of the central portion of the hyoid bone in continuity with thyroglossal duct cyst, which results in reducing the recurrence rate to approximately $20 \%$. In 1920 , Sistrunk advocated the additional contiguous removal of a core of tissue through the base of the tongue; he originally recommended excision of the foramen cecum but modified his procedure at a later date to transection in the submucosal plane to avoid entrance into the oropharyngeal cavity $[4,17]$. This form of the Sistrunk procedure remains the treatment of choice for thyroglossal duct cysts up to date.

Ethanol sclerosis therapy is introduced before as a treatment for thyroglossal duct cyst. Cystography is performed before ethanol injection to confirm that there is no extravasation and that it is a monocystic lesion [18]. However, large series with application of this technique is required to verify its efficacy.

Greatest risk of recurrence is associated with failure to follow the surgical principles of Sistrunk procedure [19]. The recurrence rate in our case was 1 out of $18(5.5 \%)$ patients who underwent sistrunk procedure, which was on agreement with that of the others [19].

Dermoid cysts in the midline and paramedian region of the neck are often clinically misdiagnosed as TGDC. In a study done by DeMello [20], 11 of 71 midline cysts proved histologically to be dermoid cysts even though they were not recognized preoperatively or intraoperatively to be so. At the time of surgical dissection 9 of these lesions actually demonstrated attachments to the hyoid bone and 6 had apparent midline tracts.

The incidence of carcinoma of TGDC is less than $1 \%$ [21-23]. There is still controversy about thyroid removal for a papillary carcinoma of TGDC. Sistrunk surgery is considered enough for TGDC carcinoma for the majority of the authors [24,25].

\section{CONCLUSIONS}

We can conclude that the diagnosis of TGDC in most of the cases is clinical. Combination of clinical assessment and 
imaging studies can improve the sensitivity for the diagnosis. Sistrunk's operation presented good results in our series with low rates of complications ( $5 \%$ ) and recurrence $(5.5 \%)$.

\section{REFERENCES}

[1] Skandalakis JE, Gray GN. Embryolgy for surgeons. Baltimore: Williams \& Wilkins, 1994

[2] Allard RH. The thyroglossal duct cyst. Head Neck Surg 1982; 5: 134-146.

[3] Telander R, Filston H. Review of head and neck lesions in infancy and children, Surg Clin North Am 1992; 72: 1429-1447.

[4] Sistrunk WW. The surgical treatment of cysts of the thyroglossal tract. Ann Surg 1920; 71: 121-124.

[5] Telander RL, Deane SA. Thyroglossal and branchial cleft cysts and sinuses. Surg Clin North Am 1977; 57: 779.

[6] Brown BM, Judd, E. Thyroglossal duct cysts and Sinuses. Am J Surg 1961; 102: 494-501.

[7] Noyek AM, Friedberg J. Thyroglossal duct and ectopic thyroid disorders. Otol Clin North Am 1981; 14: 187-201.

[8] Moussatos GH, Baffes TG. Cervical masses in infants and children. Pediatrics 1963; 32: 251-6.

[9] Roback SA, Telander RL. Thyroglossal duct cysts and branchial cleft anomalies. Semin Pediar Surg 1994; 3: 142-6.

[10] Brown RL, Azizkhan RG. Pediatric head and neck lesions. Pediatr Clin North Am 1998; 45: 889-905.

[11] Feuerstein IM, Harbert JC. Hypertrophied thyroid tissue in a thyroglossal duct remnant. Clin Nuc Med 1986; 11: 135.

[12] Katz AD, Hachigian M. Thyroglossal duct cysts: a thirty year experience with emphasis on older patients. Am J Surg 1988; 155: 7414.

[13] Dedivitis RA, Guimaraes AV. Papillary thyroid carcinoma in thyroglossal duct cyst. Int Surg 2000; 85: 109-201
[14] Ahuja AT, Wong KT, King AD, Yuen EHY. Imaging for thyroglossal duct cyst: the bare essentials. Clin Rdiol 2005; 60(2): $141-8$.

[15] Lim-Dunham JE, Feinstein KA, Yousefzadeh DK, Ben-Ami T. Sonographic demonstration of a normal thyroid gland excludes ectopic thyroid in patients with thyroglossal duct cyst. AJR Am J Roentgenol 1995; 164: 1489-1491.

[16] Schlange H. Uber Die Fistula Colli Congenita. Arch Klin Chir 1893; 46: 390-392.

[17] Sistrunk WE. Technique of removal of cysts and sinuses of the thyroglossal duct. Surg Gynecol Obstet 1928; 46: 109-112.

[18] Fukumoto K, Kojima T, Tomonari H, et al. Ethanol injection sclerotherapy for Baker's cyst, thyroglossal duct cyst, and branchial cleft cyst. Ann Plast Surg 1994; 33: 615-619.

[19] Pelausa EO, Forte V. Sistrunk revisited: a 10-year review of revision thyroglossal duct surgery at Toronto's Hospital for Sick Children. Otolaryngol 1989; 18: 325-333.

[20] DeMello DE, Lima JA, Liapis H. Midline cervical cysts in children. Arch Otolaryngol Head Neck Surg 1987; 113: 418-420.

[21] Van Vuuren PA, Balm AJ, Gregor RT, et al. Carcinoma arising in thyroglossal duct remnants. Clin Otolaryngol 1994; 19: 509-15.

[22] Peretz A, Leiberman E, Kapelushnik J, et al. Thyroglossal duct carcinoma in children: case presentation and review of the literature. Thyroid 2004; 14: 777-85.

[23] Joseph TJ, Komorowski RA. Thyroglossal duct carcinoma. Hum Pathol 1975; 6: 717-29.

[24] Kojima Y, Sakata H, Nakamura Y, Furuya N. Papillary carcinoma of the thyroid originating in a thyroglossal cyst. ORL 1996; 58: 238-241.

[25] Daou R, Aftimos G, Rahayel L. Carcinome papillaire de'veloppe dans la paroi d'un kyste du tractus thyre'oglosse. Ann Chir 1996; 50: $162-164$ 